University of Nebraska - Lincoln

DigitalCommons@University of Nebraska - Lincoln

U.S. National Park Service Publications and

Papers

National Park Service

2019

\title{
Loss of Potential Aquatic-Terrestrial Subsidies Along the Missouri River Floodplain
}

Jeff S. Wesner

David L. Swanson

Mark D. Dixon

Daniel A. Soluk

Danielle J. Quist

See next page for additional authors

Follow this and additional works at: https://digitalcommons.unl.edu/natlpark

This Article is brought to you for free and open access by the National Park Service at DigitalCommons@University of Nebraska - Lincoln. It has been accepted for inclusion in U.S. National Park Service Publications and Papers by an authorized administrator of DigitalCommons@University of Nebraska - Lincoln. 


\section{Authors}

Jeff S. Wesner, David L. Swanson, Mark D. Dixon, Daniel A. Soluk, Danielle J. Quist, Lisa A. Yager, Jerry W. Warmbold, Erika Oddy, and Tyler C. Seidel 


\title{
Loss of Potential Aquatic-Terrestrial Subsidies Along the Missouri River Floodplain
}

\author{
Jeff S. Wesner, ${ }^{1,2 *}$ David L. Swanson, ${ }^{1,2}$ Mark D. Dixon, ${ }^{1,2}$ \\ Daniel A. Soluk, ${ }^{1,2}$ Danielle J. Quist, ${ }^{1,4}$ Lisa A. Yager, ${ }^{3}$ Jerry W. Warmbold, ${ }^{1}$ \\ Erika Oddy, ${ }^{1}$ and Tyler C. Seidel ${ }^{1,5}$
}

\begin{abstract}
${ }^{1}$ Department of Biology, University of South Dakota, Vermillion, South Dakota 57069, USA; ${ }^{2}$ Missouri River Institute, University of South Dakota, Vermillion, South Dakota 57069, USA; ${ }^{3}$ National Park Service, Missouri National Recreational River, Yankton, South Dakota 57078, USA; ${ }^{4}$ Biology Department, Anoka-Ramsey Community College, Coon Rapids, Minnesota 55433, USA; ${ }^{5}$ Department of Ecology, Evolution and Behavior, University of Minnesota, Saint Paul, Minnesota 55108, USA
\end{abstract}

\begin{abstract}
The floodplains of large rivers have been heavily modified due to riparian development and channel modifications, both of which can eliminate shallow off-channel habitats. The importance of these habitats for aquatic organisms like fishes is well studied. However, loss of off-channel habitat also eliminates habitats for the production of emerging aquatic insects, which subsidize riparian consumers in terrestrial food webs. We used field collections of insect emergence, historical mapping, and statistical modeling to estimate the loss of insect emergence due to channel modifications along eight segments of the Missouri River (USA), encompassing 1566 river km, between 1890 and 2012 . We estimate annual production of emerging
\end{abstract}

Received 22 November 2018; accepted 15 April 2019

Electronic supplementary material: The online version of this article (https://doi.org/10.1007/s10021-019-00391-9) contains supplementary material, which is available to authorized users.

Authors' Contributions Jeff Wesner conceived the study, performed the research, analyzed the data, and wrote the paper. David Swanson performed the research, analyzed the data, and wrote the paper. Mark Dixon performed the research and wrote the paper. Daniel Soluk wrote the paper. Danielle Quist performed the research and analyzed the data. Lisa Yager performed the research and wrote the paper. Jerry Warmbold performed the research and wrote the paper. Erika Oddy performed the research and wrote the paper. Tyler Seidel performed the research and wrote the paper.

*Corresponding author; e-mail: jeff.wesner@usd.edu aquatic insects declined by a median of $36,000 \mathrm{kgC}$ (95\% CrI: 3000 to 450,000 ) between 1890 and 2012 (a 34\% loss), due to the loss of surface area in backwaters and related off-channel habitats. Under a conservative assumption that riparian birds obtain $24 \%$ of their annual energy budget from adult aquatic insects, this amount of insect loss would be enough to subsidize approximately 790,000 riparian woodland birds during the breeding and nesting period (May to August; 95\% CrI: 57,000 to $10,000,000)$. Most of the loss is concentrated in the lower reaches of the Missouri River, which historically had a wide floodplain, a meandering channel, and a high density of off-channel habitats, but which were substantially reduced due to channelization and bank stabilization. Our results indicate that the loss of off-channel habitats in large river floodplains has the potential to substantially affect energy availability for riparian insectivores, further demonstrating the importance of maintaining and restoring these habitats for linked aquatic-terrestrial ecosystems.

Key words: aquatic-terrestrial linkages; insect emergence; floodplain; ecological subsidies; modeling. 


\section{HighLights}

- Habitat loss along the Missouri River floodplain is substantial over 122 years.

- Lost habitat means lost aquatic insect production on the landscape.

- We estimate that annual insect emergence declined by $\sim 36,000 \mathrm{kgC}$ since 1890 (34\% loss) in our study segments.

\section{INTRODUCTION}

Channelization, dams, and riparian development have altered the structure and function of rivers and their associated floodplain habitats (Morris and others 1968; Poff and others 1997; Wohl and others 2015; Kennedy and others 2016). In particular, channelization and dam-induced changes to the flow of water and sediment have severed the connections between the river and its floodplain, causing dramatic losses in off-channel habitat (Morris and others 1968; Funk and Robinson 1974; Hamilton 2009; Yager and others 2013). Offchannel habitats that surround rivers, such as backwaters, shallow side-channels, sloughs, and oxbow lakes, can harbor unique taxa and have high secondary productivity of invertebrates (Benke 2001; Whiles and Goldowitz 2005). They also represent crucial reproductive habitats for fish, and their loss is linked to the decline of some freshwater fishes (Grubaugh and Anderson 1988; Galat and others 1998; Aarts and others 2004).

Although the consequences for these losses are relatively well studied for some freshwater organisms like fishes, their effects on landscape-level insect production and potential aquatic-terrestrial subsidies are not well known. Adult aquatic insects are ubiquitous in freshwater habitats, where they develop as larvae. When they emerge as winged adults to disperse and reproduce, they are vulnerable to terrestrial insectivores, such as birds, spiders, reptiles, and bats (Nakano and Murakami 2001; Sabo and Power 2002; Baxter and others 2005; Epanchin and others 2010; Allen and Wesner 2016). This flux of biomass from water to land represents a substantial ecological subsidy that can alter the structure and functioning of terrestrial food webs by enhancing recipient consumer populations (Epanchin and others 2010) or transferring nutrients to terrestrial detrital pools (Hoekman and others 2011; Bartrons and others 2013).

The production of adult aquatic insects from freshwater ecosystems has been relatively well studied in rivers and lakes (Gratton and Vander Zanden 2009; Bartrons and others 2013; Richardson and Sato 2015). A global meta-analysis revealed that insect emergence represents a flux of between 0.07 and $1.22 \mathrm{gC} / \mathrm{m}^{2} / \mathrm{y}(95 \% \mathrm{CI})$ from lakes and between 0.4 and $3.1 \mathrm{gC} / \mathrm{m}^{2} / \mathrm{y}(95 \% \mathrm{CI})$ from rivers (Gratton and Vander Zanden 2009). For rivers, these estimates are largely limited to the main channel, yet production in off-channel habitats can equal or exceed production in the main channel. For instance, insect emergence from riparian sloughs near the Platte River, a braided river in the central USA, ranged from 0.06 to 2.4 $\mathrm{gC} / \mathrm{m}^{2} / \mathrm{y}$ across sites (Whiles and Goldowitz 2001), similar to the global range of flux from lakes and rivers (Gratton and Vander Zanden 2009). In the Ogeechee River (Georgia, USA), macroinvertebrate production of wetted off-channel habitat in the floodplain was higher than production in the channel, due primarily to the large amount of surface area represented by off-channel habitat relative to the mainstem (Benke 2001). Given the importance of aquatic-terrestrial subsidies to terrestrial ecosystems and the global loss in floodplain habitat (Poff and others 1997; Wohl and others 2015), it is crucial to understand how the loss of off-channel habitats influences aquatic insect emergence at the landscape scale.

The Missouri River is the longest river in North America, spanning a length of 3768 river $\mathrm{km}$, and it has experienced large losses in off-channel habitat (Galat and others 2005; Quist 2014). For most of its length, the Missouri River flows through the relatively flat terrain of the Midwestern USA. Prior to the late 1800s, that terrain allowed the river to meander across wide floodplains, creating extensive networks of off-channel aquatic habitats, especially on the lower Missouri (Galat and others 2005). Beginning in the late 1800 s, the river was extensively modified along nearly all of its length. The lower segment $(\sim 1200 \mathrm{~km})$ was channelized for navigation, which deepened the main channel, eliminated the ability of the river to meander, and in turn eliminated most of the off-channel habitat (Funk and Robinson 1974; Quist 2014). In the mid1900s, six mainstem dams were built on the upper two-thirds of the river, changing much of the main channel from lotic to lentic habitat and inundating any remaining off-channel habitats (Whitley and Campbell 1974; Galat and others 2005). In addition to altering the aquatic habitat in the main channel and floodplain, these modifications also impacted the riparian vegetation and forest structure along the undammed sections of the river, largely by eliminating the flood-pulse dynamics that gener- 


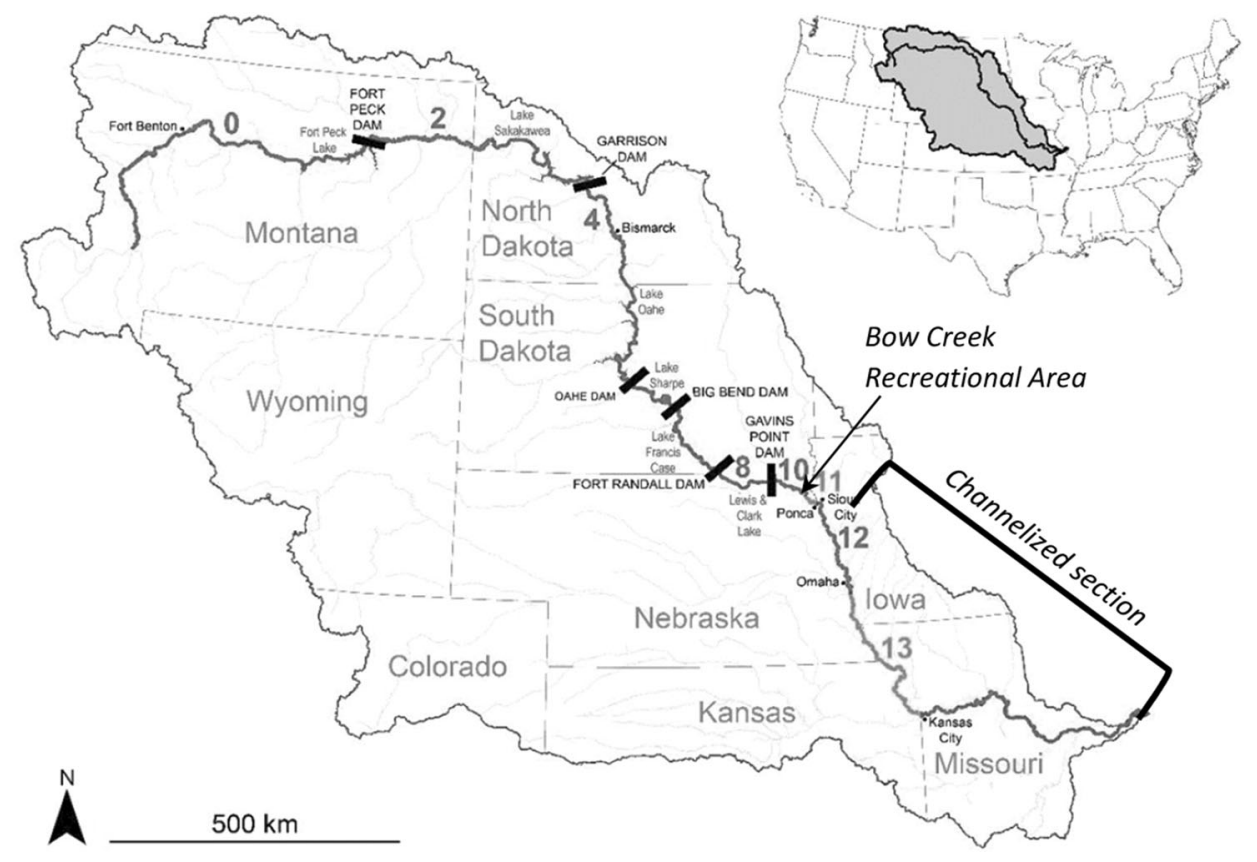

Figure 1. A map of the study segments within the Missouri River. Black bars represent mainstem dams. Numbered segments indicate the study segments for which we modeled insect emergence using historical and current estimates of off-channel habitat area.

ated open sandbars for cottonwood forest regeneration (Johnson and others 1976; Dixon and others 2012). Outside of the headwaters, only a few segments of unchannelized or undammed river exist today, two of which include the "39-mile" and "59-mile" segments designated as the Missouri National Recreational River (MNRR) in southeast South Dakota and northeast Nebraska, USA (segments 8 and 10, respectively, Figure 1).

Here, we used field collections of aquatic insect emergence in the MNRR, along with historical estimates of off-channel habitat area, to estimate the amount of insect production that has been lost due to the removal of floodplain habitat in the Missouri River between the 1890s and 2012. We chose these years to take advantage of existing maps of off-channel habitat available across eight segments of the river during that time span (Quist
2014). We then combined this result with field measures of riparian bird densities and allometric estimates of energetic requirements to estimate how losses of insect emergence may affect woodland insectivorous birds along the Missouri River.

\section{MeThODS}

\section{Insect Collection}

We collected emerging aquatic insects using floating emergence traps $\left(0.36 \mathrm{~m}^{2}, 500 \mu \mathrm{m}\right.$ mesh, Cadmus and others 2016) in four backwaters along the Missouri River (Table 1). The backwaters were located in Bow Creek Recreation Area within the Missouri National Recreational River (lat: 42.780682, long: - 97.146950) (Figure 1). Two backwaters were in an old side channel, one below

Table 1. Site Descriptions for Four Backwaters in the Missouri National Recreational River From Which Insect Emergence was Collected

\begin{tabular}{|c|c|c|c|c|c|c|c|}
\hline \multirow[t]{2}{*}{ Site } & \multirow[t]{2}{*}{ Area $\left(\mathrm{m}^{2}\right)$} & \multirow[t]{2}{*}{ Max depth (m) } & \multirow[t]{2}{*}{ Max temp. $\left({ }^{\circ} \mathrm{C}\right)$} & \multicolumn{4}{|c|}{ Emergence collected } \\
\hline & & & & 2014 & 2015 & 2016 & 2017 \\
\hline Below dam & 448 & 0.6 & 25.7 & Jul-Aug & Jun-Jul & May-Sep & May-Jul \\
\hline Above dam & 4500 & 0.6 & 27.5 & & & May-Sep & May-Jul \\
\hline Large pool & 5760 & $>2$ & $\mathrm{n} / \mathrm{a}$ & & & May-Sep & \\
\hline Small pool & 250 & 1 & $\mathrm{n} / \mathrm{a}$ & & & May-Sep & \\
\hline
\end{tabular}


and one above a temporary beaver dam (hereafter "below dam" and "above dam"). These two sites are located $\sim 0.4 \mathrm{~km}$ from the main channel of the Missouri River, and the side channel is connected to the main channel in most years (Warmbold 2016). The third site is a large backwater that is $\sim 0.1 \mathrm{~km}$ from the mainstem (hereafter "large pool") and is intermittently connected to the mainstem. The fourth site is a small isolated backwater that is disconnected from the mainstem (hereafter "small pool").

Emerging aquatic insects were collected from the site below the beaver dam in all four years (2014, 2015, 2016, and 2017). We also collected emergence from the site above the beaver dam in 2016 and 2017. Emergence data from the large pool and small pool were collected in 2017. Collections occurred during 4-6 day intervals during the summer months in all years, and in late spring and fall in 2017 (Table 1). Collection methods were identical across years, and followed established protocols (Malison and others 2010; Warmbold 2016; Warmbold and Wesner 2018). Briefly, we anchored 1-9 traps per site, to the substrate with tent stakes, arranging them haphazardly within each pool on water that was between $\sim 0.25$ and $1.5 \mathrm{~m}$ deep. The number of traps per site depended on habitat area (Table 1) and the purpose of the associated study (see Table S1). The backwaters generally had little emergent vegetation (due in part to the presence of invasive Silver Carp (Hypophthalmichthys molitrix) and Grass Carp (Ctenopharyngodon idella) and a homogenous substrate. The traps contained collection bottles with mesh netting that provided surface area for the insects to colonize once the emerged (Cadmus and others 2016). We removed the bottles and replaced them every 4-6 days. In addition, insects were aspirated from the inside of the traps on the same days by gently lifting the trap to minimize the chance of insect escape. All insects were stored at $4^{\circ} \mathrm{C}$ and sorted to family or species in the laboratory. Traps were cleared of debris between collections.

The emergence protocols were repeated as part of four separate studies (Table S1). Three of those studies included fish exclusion experiments, in which traps were set inside and outside of fish exclusion cages (for example, Warmbold and Wesner 2018). For those studies, we only used data from the traps that were outside of the fish exclusion cages. The fourth study (Oddy and others unpublished, Table S1) did not include exclusion cages. As a result, all emergence data in the present study represent only samples of ambient emergence from the backwaters. Any substrate disturbance as a result of our sampling efforts did not appear to affect emergence samples-based comparisons with falsebottomed cages (which prevented substrate disturbance during collection) (Warmbold (2016)).

To determine dry mass, we weighed between 1 and 199 individuals from each taxon in most traps and calculated mg dry mass per individual. This resulted in 660 total estimates of individual insect dry mass of adult aquatic insects from collections in 2015 (629 estimates) and 2016 (31 estimates). The number of samples differed between years due to the experimental design (more traps in 2015), and also because insect weights in 2016 were derived by weighing 10 or more insects per weighing event, while those in 2015 included both weights of combined individuals and of single individuals. Because dry mass appeared similar between years (Figure S1), we did not weigh insects in 2017. The taxonomic composition of the weighed samples was similar to that of the overall emergence samples; Chironomidae represented $95 \%$ of weighed samples and $>97 \%$ of emergence samples. The remaining weighed taxa were Ephemeroptera (23/ 660 or $3 \%)$, Odonata $(5 / 660$ or $<0.01 \%)$ and Trichoptera $(5 / 660$ or $<0.01 \%)$.

\section{Analysis}

We used Bayesian models to estimate the posterior distribution of a) mean individual dry mass and b) daily emergence dry mass from May to September. For individual dry mass, we used an intercept-only generalized linear model with individual dry mass $(\mathrm{mg})$ as the response variable with a Gamma likelihood and a log link. We specified a vague normal prior distribution for the intercept with a mean of 0 and sd of 2, that is, $N(0,2)$ (Table S2). This model did not include month as a predictor, because plots of samples over each month suggested that the dry mass of individual insects was similar over time (Figure S1).

To calculate dry mass of the entire emergence sample, we multiplied the number of insects in each sample by a random sample from the posterior distribution of individual dry mass. This was converted to daily production per unit area by dividing by the trap area $\left(0.36 \mathrm{~m}^{2}\right)$ and the number of days that traps were set. We then modeled emergence production $\left(\mathrm{mgDM} / \mathrm{m}^{2} / \mathrm{d}\right)$ from May to September using a generalized additive mixed model (GAMM) with daily emergence production as the response variable, day of the year as a smoothed predictor variable, and location and year as random effects. The degree of smoothing was optimized to avoid 
overfitting via generalized cross-validation (Wood 2017). We chose to use a GAMM because emergence patterns were highly nonlinear over time and GAMMs are ideal for modeling such data (Hastie 2017). We used a weakly informative prior for the intercept based on estimates of mean daily emergence from 62 lentic studies of emergence (Table S2). All other parameters contained vague priors based on standard probability distributions (for example, half-Cauchy, Student's t, gamma) (Table S2). Graphical comparisons of the prior and posterior distributions indicated that prior influence on the outcome was weak relative to the influence of data (Figure S2).

After fitting the GAMM, we estimated cumulative insect production over all months (May-Sep) by first simulating 112 days of emergence from the posterior distribution of the GAMM. This generated 1000 estimates of the posterior distribution of daily emergence for each of the 112 days. We then summed across the 112 days at each iteration to generate a single posterior distribution of cumulative insect emergence from late May to midSeptember. Because the backwaters are typically under ice from early November through midMarch, we assume that this approximates annual insect production in the system. This is a conservative estimate that assumes zero emergence between ice out in mid-March and our earliest emergence collection in late May, and also zero emergence between our last collection in early September and ice cover in early November. Although emergence is unlikely to truly be zero on these dates, we estimate that it is likely to be trivially small compared to emergence over the summer (see Emergence before and after our sample dates, Supplementary Information).

For all models, the posterior distribution was estimated using the Hamiltonian Monte Carlo algorithm in rstan (Stan Development Team 2016) via the brms package (Bürkner 2017) in R (v3.4.2, (R Core Team 2017). We ran 4 chains with 2000 iterations each, with the first 1000 discarded as warmup.

\section{Annual Emergence Production for 1566 $\mathrm{km}$ of Missouri River}

In addition to describing emergence at the four backwaters using the fitted regression line and credible interval, we also used the predict() function from brms to predict emergence at new sites by sampling from the posterior distribution. Predicted emergence has wider credible intervals than fitted estimates because it incorporates uncertainty using the standard deviation of the random effects term. We multiplied the predicted emergence distribution by the total surface area of off-channel habitats in eight unimpounded segments, encompassing 1566 river $\mathrm{km}$ (Figure 1; Table S3). The surface area of off-channel habitats in each segment was calculated for the early 1890s, mid-1950s, 2006, and 2012 by Quist (2014) (Table S4), using interpretation of historical maps (for 1890s) and aerial photography (for 1950s-2012). Quist (2014) estimated the surface area of 10 off-channel habitat types, but we limited our analysis to four of those habitats that most closely matched the habitats from which we sampled emergence (backwaters, backups, floodplain lakes/oxbows, and restored backwaters). This allowed us to estimate the amount of emergence production lost over the past 122 years due to channelization, channel incision, and drainage of backwaters (Yager and others 2013; Quist 2014). Estimates of habitat area were available for all segments and years, with the exception of segments 0 and 2 in 2012, and segment 11 in the 1950s.

\section{Bird Physiological Requirements and Abundance Estimates}

To determine how many riparian woodland birds our emergence samples could support, we calculated community energetics for the terrestrial riparian bird community from bird density estimates generated from bird surveys in different successional stages of riparian forest in the 39-mile and 59-mile reaches of the MNRR (Benson 2011; Munes and others 2015). We calculated field metabolic rates for all bird species ( 36 total) that were regular components of the breeding riparian forest avifauna. These estimates do not include swallows (Family Hirundinidae), which are major consumers of aquatic insects but are usually associated with riverine habitats rather than directly with riparian forests in the study area (Tallman and others 2002). We calculated field metabolic rates from Anderson and Jetz (2005):

$$
\begin{aligned}
\log _{10} \text { FMR }= & 0.7582 \\
& +0.6979\left(\log _{10} \mathrm{Mb}\right)-0.0075(\mathrm{Ta}) \\
& +0.018(\mathrm{DL})
\end{aligned}
$$

where FMR is field metabolic rate (kJ/day), $\mathrm{Mb}$ is body mass (grams), Ta = mean daily temperature $\left({ }^{\circ} \mathrm{C}\right)$, and $\mathrm{DL}=$ mean day length (hours). We then multiplied the FMR from this equation by 1.1921 (the antilog of the "Group" exponent for birds in Anderson and Jetz (2005)) to determine FMR for a particular bird species in the present study. 


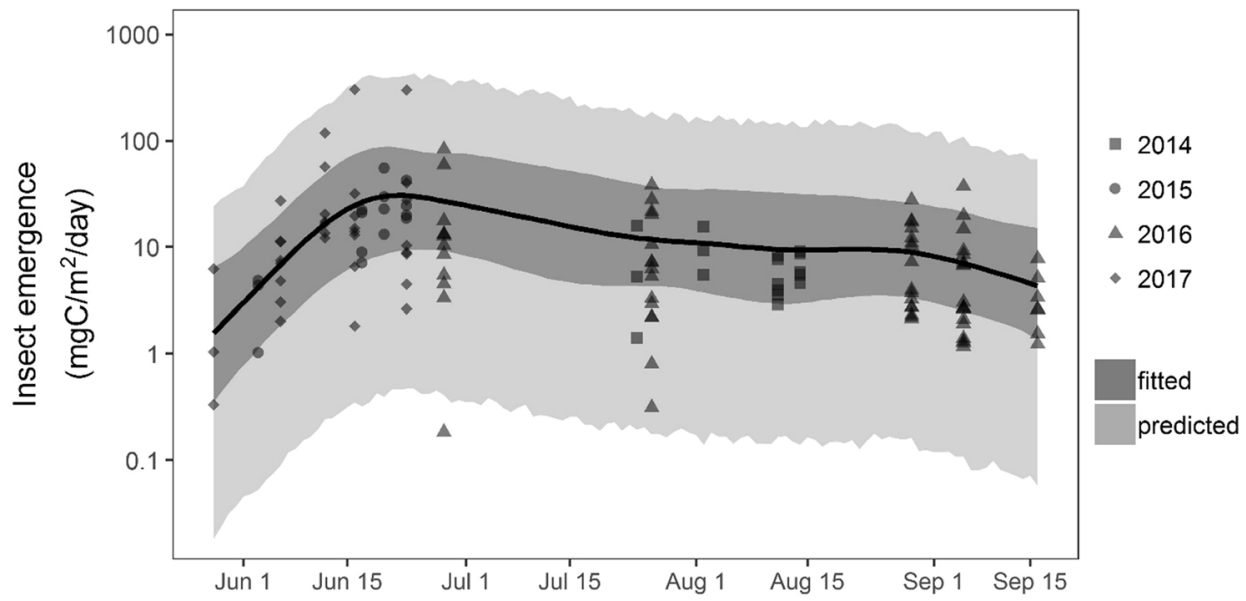

Figure 2. Fitted and predicted daily insect emergence production using a generalized additive mixed model. Each symbol represents a single emergence trap at one of the four sites. The solid line is the median emergence. The dark gray represents the $95 \%$ credible interval for emergence at the four collection sites. The light gray represents the $95 \%$ prediction interval for new sites.

Table 2. Estimates of the Annual Production of Insect Emergence from Missouri River Backwaters in Units of Grams of Dry Mass, Grams of Carbon, and kJ

\begin{tabular}{|c|c|c|c|c|c|c|}
\hline \multirow[t]{2}{*}{ Units } & \multicolumn{3}{|l|}{ Fitted } & \multicolumn{3}{|c|}{ Predicted } \\
\hline & Low95 & Median & High95 & Low95 & Median & High95 \\
\hline $\mathrm{gDM} / \mathrm{m}^{2} / \mathrm{y}$ & 1.2 & 3.2 & 9 & 0.3 & 3.3 & 36 \\
\hline $\mathrm{gC} / \mathrm{m}^{2} / \mathrm{y}$ & 0.6 & 1.5 & 4 & 0.1 & 1.5 & 17 \\
\hline $\mathrm{kJ} / \mathrm{m}^{2} / \mathrm{y}$ & 26 & 71 & 186 & 14 & 70 & 313 \\
\hline
\end{tabular}

Fitted estimates are summaries of the posterior distribution based on the four sites from which emergence was directly measured. Predicted estimates are posterior predictions for new sites. The predicted estimates were used to measure production at the segment and river scale. "low95" and "high95" are the lower and upper $95 \%$ credible intervals.

We used mean daily temperatures and day length for June, the period of maximum insect emergence, for Vermillion, SD, which is in the middle of the 59-mile reach of the MNRR (segment 10). For body mass (Mb) values applied to field metabolic rate calculations, we used summer data from local bird populations, if available (Dutenhoffer and Swanson 1996; Swanson and Liknes 2006; Swanson 2010), and used data from Dunning (2007) when local data were not available. When $\mathrm{Mb}$ values were provided separately for males and females in (Dunning 2007), we used the average value for the two sexes to calculate field metabolic rates. We then multiplied density estimates (birds/ ha) for each species by the field metabolic rate $(\mathrm{kJ} /$ d) for that species to compute species-specific energetic cost estimates $(\mathrm{kJ} / \mathrm{d} / \mathrm{ha})$. We summed the species-specific energetic cost estimates to compute a community energetic cost estimate $(\mathrm{kJ} / \mathrm{d} / \mathrm{ha})$ for all birds for each of six successional stage categories of riparian forest.

\section{Test for Bias and Prior Sensitivity}

Because our model contained emergence data from a combination of different sites, years, and months, we were concerned that the estimates obtained from the full generalized additive model might be biased by the different sampling efforts at each site. To test for this potential bias, we re-ran the analysis four times, leaving out one of the four sites each time. We then compared the predictions of annual emergence from these four models to that of the full model (Table S5). To examine the influence of the priors, we re-ran the model with two alternative prior specifications for the intercept. One model contained a wider standard deviation $(\log (100)$ instead of $\log (50))$, and the other model 


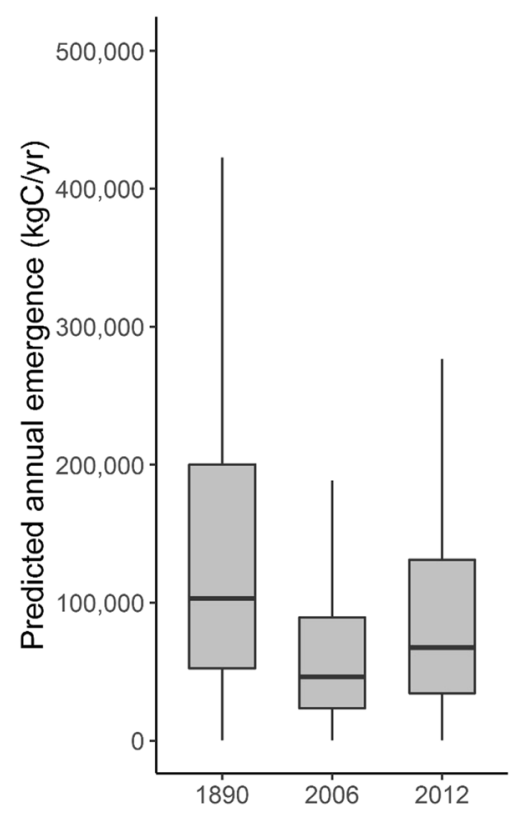

Figure 3. Predicted annual aquatic insect emergence from backwaters along six segments of the Missouri River from 1890 to 2012. Boxplots summarize the posterior predictive distribution of emergence $(\mathrm{kgC} / \mathrm{y})$ from the generalized additive model (see text). Those predictions were multiplied by the area of backwaters in each segment and year as estimated by Quist (2014). Boxes show the median and quartiles. Whiskers show 1.5 the inter-quartile range. Results for the 1950s are excluded, because no data were available in that year from segments 11 and 12, which exported the vast majority of river-wide insect biomass.

contained a nearly flat prior centered on zero with a wide standard deviation: $N(0,1000)$.

\section{Unit Conversion and Precision}

All data were analyzed initially as mg of dry mass, but we also report results in units of carbon or kilojoules (kJ). Conversions from dry mass to carbon used established conversion factors (Gratton and Vander Zanden 2009), in which the percent of insect dry mass that is ash was first subtracted from the total dry mass. We assumed that insect dry mass contained $5.3 \%$ ash based on average ash content from 7 chironomid species analyzed by Cummins and Wuycheck (1971). For insects, ashfree dry mass (AFDM) contains $\sim 50 \%$ carbon (Benke 2001). Thus, we assumed that the amount of carbon in insects was $0.5^{*} \mathrm{AFDM}$. To convert dry mass to $\mathrm{kJ}$, we assumed that a gram of insect dry mass contained $23.012 \mathrm{~kJ}$ of energy based on estimates from Cummins and Wuycheck (1971).

To avoid overstating precision, we rounded all estimates of annual river-wide flux to the nearest thousand (for example, 36,278 $\mathrm{kgC}$ would be reported below as 36,000$)$.

\section{Data and R code}

Data and R code to reproduce models, figures, and summary statistics are available at https://doi.org/ 10.5281/zenodo.2582597.

\section{Results \\ Insect Community}

Aquatic insect emergence was dominated by Diptera, which represented more than $97 \%$ of dry mass in each year. Of the Diptera, nearly all $(96 \%)$ were Chironomidae, with less than $1 \%$ composed of Ceratopogonidae, Dolichopodidae, and Tipulidae. The remaining insect taxa were Ephemeroptera, Odonata, and Trichoptera.

\section{Insect Emergence}

Insect emergence was lowest in late May, when it ranged between 0.6 and $7 \mathrm{mgC} / \mathrm{m}^{2} /$ day $(95 \% \mathrm{CrI})$ with a median of 2 (Figure 2). It peaked in midJune, ranging between 11 and $78 \mathrm{mgC} / \mathrm{m}^{2} /$ day (95\% CrI) with median of 31 , and then declined slowly thereafter to $\sim 4 \mathrm{mgC} / \mathrm{m}^{2} /$ day by late September (Figure 2). In total, 0.6 to $4 \mathrm{gC} / \mathrm{m}^{2}$ (95\% CrI) emerged from backwaters annually, with a median of 1.5 (Table 2).

Based on the posterior predictive distribution, new sites are likely to produce between 0.1 and 17 $\mathrm{gC} / \mathrm{m}^{2} / \mathrm{y}(95 \% \mathrm{CrI})$ with a median of 1.5 (Table 2 ). Multiplying that production by the area of offchannel habitats along the lower six segments (949 river $\mathrm{km}$; upper two segments did not have estimates of habitat area in 2012) of the Missouri River revealed that annual insect production in 1890 ranged between 13,000 and 968,000 kgC/y $(95 \%$ CrI), with a median of 105,000 . In 2012, predicted production ranged between 8000 and $633,000 \mathrm{kgC/}$ y $(95 \%$ CrI), with a median of 68,000 (Figure 3 ). That represents a median loss of $36,000 \mathrm{kgC}$ in 2012 compared to 1890 , a 34\% decline (Table 3). There is considerable uncertainty in this estimate, with a $95 \%$ probability that the decline was between 7,000 and 160,000 kgC (Table 3).

The decline in emergence was heavily concentrated in the lower segments, which historically contained the largest amount of off-channel habitat, and thus the largest amount of potential insect emergence (Figure 4). For example, segment 12 accounted for $67 \%$ of the decline in emergence and 
Table 3. Summary of the Posterior Predictive Distribution of the Change in Insect Emergence From Off-channel Habitats Between the 1890s and 2006 or 2012

\begin{tabular}{lllll}
\hline Start & End & \multicolumn{3}{l}{ Predicted change (kgC/y) } \\
\cline { 3 - 5 } & & Low95 & Median & High95 \\
\hline 1890s & 2006 & $-812,000$ & $-57,000$ & -4000 \\
$1890 \mathrm{~s}$ & 2012 & $-507,000$ & $-36,000$ & -3000
\end{tabular}

Data are for segments 4-13 in the Missouri River. low 95 and high95 are the lower and upper $95 \%$ credible intervals. Comparisons to the 1950 s are excluded, because no data were available in the 1950s from segment 11 .

segment 13 accounted for an additional $21 \%$, both of which are channelized segments.

Although river-wide emergence from off-channel habitats has declined substantially over time, estimated emergence from some individual segments increased since the 1890s. This is most dramatic in segment 8 (Figure 4), where annual emergence initially declined by $5 \mathrm{kgC} / \mathrm{m}$ (95\% CrI: 0.4 to 72 ) from the 1890 s to $1950 \mathrm{~s}$. By 2012 , emergence had increased by $30 \mathrm{kgC} / \mathrm{m}$ (95\% CrI: 2 to 370 ) relative to the 1890 's baseline.

\section{Test for Bias and Prior Sensitivity}

We re-ran the analysis four times, each time leaving out collections from one site. Median annual production across the four models ranged from 1.3 to $1.9 \mathrm{gC} / \mathrm{m}^{2} / \mathrm{y}$. This was similar to the median for the full model of $1.5 \mathrm{gC} / \mathrm{m}^{2} / \mathrm{y}$ (Table S5). There was strong overlap in the posterior predictive distributions of all models (Figure S3), with the 95\% credible intervals for all models ranging from less than 1 to more than $61 \mathrm{gC} / \mathrm{m}^{2} / \mathrm{y}$ (Table S5), indicating that no single site dominated the results of the full model.

Prior specification had almost no influence on the posterior. This is indicated by the strong overlap in the posterior predictive distributions from the original model compared to models with either a wider standard deviation on the intercept or a mean centered on zero for the intercept (Figure S6).

\section{Bird Physiological Requirements and Abundance Estimates}

Bird community energetic costs ranged from 3800 to $4600 \mathrm{~kJ} \mathrm{~d}^{-1} \mathrm{ha}^{-1}$ in the different successional stages of Missouri River riparian forests (Figure S5). Community energetic costs were generally greatest for the avifauna of intermediate aged cottonwood

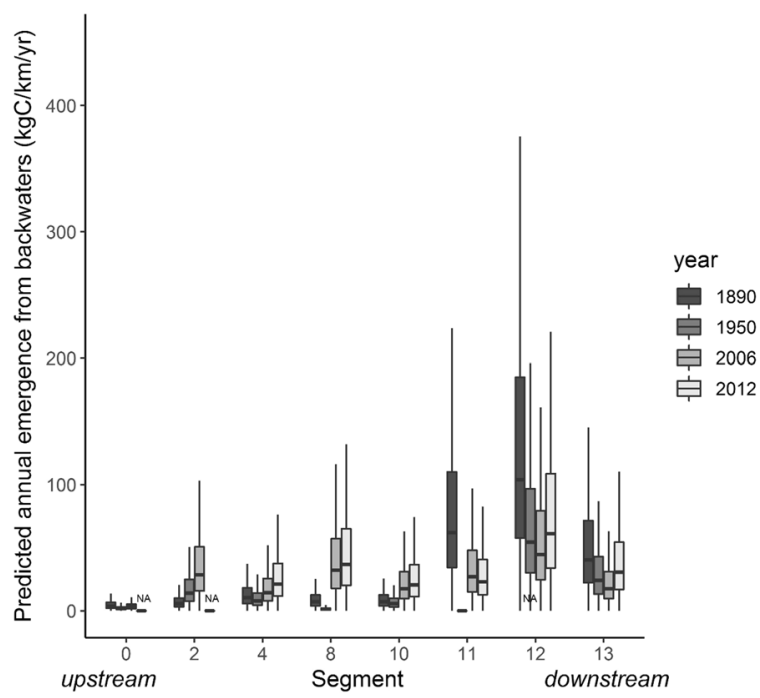

Figure 4. Predicted annual aquatic insect emergence from backwaters along 8 segments of the Missouri River (0 to 13 is upstream to downstream). Boxplots summarize 1000 simulated predictions of emergence per river $\mathrm{km}$ from the generalized additive model (see text). Those predictions were multiplied by the area of backwaters in each segment and year as estimated by Quist (2014). Boxes show the median and quartiles. Whiskers show 1.5 the inter-quartile range.

forest and lowest for old cottonwood forest, differing by only $21 \%$ on average. Early successional habitats (CWl and NCW in Figure S5), which are often those nearest the river and therefore potentially the most likely to receive aquatic subsidies, produced intermediate levels for bird community energetics. For an average sized backwater in the MNRR, such as Gunderson Backwater (approximately 2.4 ha), near Vermillion, SD, this amounts to aquatic subsidies ranging from approximately $2000 \mathrm{~kJ} / \mathrm{d}$ in late May to $24,000 \mathrm{~kJ} / \mathrm{d}$ in mid-June to $3000 \mathrm{~kJ} / \mathrm{d}$ in mid-September. These energetic subsidies could support the entire terrestrial adult breeding riparian forest bird community (Table S6) on 0.4 to 0.5 ha in late May, on 5 to 6 ha in midJune, and on 0.7 to 0.8 ha in mid-September. These estimates are derived using the minimum (CW4) and maximum (CW3) average values for bird community energetics, respectively, for the different successional stages of cottonwood and noncottonwood forest along the MNRR (Figure S5). The median loss of insect emergence across the lower six segments of the Missouri River is equivalent to the amount of energy needed to support $\sim 190,000$ (95\% CrI: 13,000 to $2,800,000$ ) riparian woodland birds for 120 days (the approximate length of the migration and breeding season), assuming community energetic requirements of 
$4600 \mathrm{~kJ} / \mathrm{d} / \mathrm{ha}$, and a mean density of $59 \mathrm{birds} / \mathrm{ha}$ (Table S6). When assuming an energetic requirement of $3800 \mathrm{~kJ} / \mathrm{d} / \mathrm{ha}$, the estimate increases to $\sim 230,000$ birds supported (16,000 to $2,800,000)$.

\section{Discussion}

The most important result of this study is that offchannel habitats in the Missouri River represent a substantial source of emerging aquatic insect production, but that production has been drastically reduced due to habitat loss over 122 years. In the early 1890s, our lower six study segments had a length of $1062 \mathrm{~km}$ (Figure 1). Predicted insect emergence in the off-channel habitat in these segments totaled $\sim 180,000 \mathrm{kgC} / \mathrm{y}$ (median). By 2012 , the river along our study segments had been shortened by $128 \mathrm{~km} \mathrm{(12 \% ),} \mathrm{due} \mathrm{largely} \mathrm{to} \mathrm{chan-}$ nelization below Sioux City, IA (USA, downstream of segment 10) (Quist 2014). Channelization eliminated nearly all the off-channel floodplain habitat in this river section (Morris and others 1968; Quist 2014). As a result, predicted aquatic insect emergence in the lower six segments in 2012 was $\sim 34 \%$ lower than emergence in 1890 , resulting in lost yearly insect emergence totaling $\sim 36,000 \mathrm{kgC}$. The decline in emergence due to habitat loss is based on direct estimates of emergence, which indicated moderate insect production. Median emergence from our four collection sites was $1.5 \mathrm{gC} / \mathrm{m}^{2} / \mathrm{y}$ (fitted median), which was lower than mean emergence across 62 global lentic habitats $\left(2.8 \mathrm{gC} / \mathrm{m}^{2} / \mathrm{y}\right.$; Figure $\left.\mathrm{S} 4\right)$. In five offchannel habitats along the Platte River, NE (USA), a large, braided river in the Great Plains, USA, insect emergence production ranged from 0.06 to 2.4 $\mathrm{gC} / \mathrm{m}^{2} / \mathrm{y}$ across habitats (Whiles and Goldowitz 2001).

Based on estimates of energetic requirements for woodland bird communities, the amount of emergence from Missouri River off-channel habitats in the early 1890s could have supported $\sim 550,000$ woodland birds for 120 days, approximately the length of the breeding and nesting season. This is a conservative estimate based on a mature forest bird community that uses $4656 \mathrm{~kJ} / \mathrm{d}$, the most energetically costly successional stage community in our dataset. By 2012, the number of birds that could be supported at that level was $\sim 350,000$, a $36 \%$ decline. These estimates assume that riparian bird diets consist only of adult aquatic insects, which is almost certainly incorrect. Riparian forest birds consume aquatic insects as a significant fraction of their diets (Nakano and Murakami 2001), but that fraction is likely less than $25 \%$ on average.
Nakano and Murakami (2001) found that the bird community of a temperate forest obtained $\sim 24 \%$ of their annual energy budget from emerging aquatic insects. In studies of migratory birds from riparian forests in our study section (segment 10), aquatic insects represented $5.7 \%$ of all dietary items of the spring (mid-April to early June) migrant bird community and $14.6 \%$ of the fall (mid-August to late October) migrant bird community (Liu and Swanson 2014; Liu 2015). If we conservatively assume that riparian birds in the MNRR obtain $\sim 10 \%$ of their annual energy budgets from emerging aquatic insects (the average of their fall and spring aquatic insect use), then the loss in emergence from 1890 to 2012 is enough to remove dietary subsidies from $\sim 1,900,000$ birds. However, because aquatic insect emergence is higher in midJune and July than it is during migratory periods, it seems likely that aquatic subsidies to terrestrial bird communities might also be higher during summer than during migratory periods. We do not have dietary estimates for birds during this time period, but if the bird communities obtained $24 \%$ of their annual energy budget - the estimate from Nakano and Murakami (2001) - then the loss in emergence is still enough to subsidize $\sim 790,000$ birds.

Although river-wide emergence declined overall, emergence in some individual segments increased since the 1890s. Most of these increases are likely caused by fluvial geomorphic processes associated with the construction of large mainstem dams (Volke and others 2015). For example, the increase in predicted emergence in segment 8 was largely caused by an increase in off-channel habitat in that segment due to sediment aggradation where the Niobrara River enters Lewis and Clark Lake, a large reservoir constructed in the 1950s (Quist 2014). This aggradation created a new delta containing shallow, off-channel aquatic habitats that did not exist before the construction of the dams (Volke and others 2015). Similar processes likely explain the increases in estimated emergence in segments 2 and 4, which also flow into large reservoirs constructed in the 1950s and 1960s and show associated delta formation at their downstream end. The factors related to an increase in backwater area (and estimated emergence) in segment 10 are less clear, as this reach does not contain a downstream dam and reservoir (Yager and others 2013). Regardless of their causes, the overall contribution of these increases to the total amount of predicted emergence in the river is small relative to the large losses in the lower reaches. Segment 12 lost $\sim 49$ $\mathrm{kgC} / \mathrm{km}$ between the $1890 \mathrm{~s}$ and 2012 due to channelization of the mainstem and conversion of 
the floodplain to agriculture or urban development. That loss is 1.5 times higher than the amount gained in segment 8 over the same period. Moreover, segment 12 is 224 river $\mathrm{km}$ long, whereas segment 8 is only 62 river $\mathrm{km}$ long. When we multiply the per $\mathrm{km}$ loss in emergence by the length of each segment, the losses from the lower segments, particularly segments 12 and 13, dominate the total river-wide loss, accounting for more than $80 \%$ of lost emergence production (Figure S7). These lower, channelized segments historically contained the highest natural density of off-channel habitats and were also the most heavily modified through channelization. Thus, while human modifications to the river channel have caused both increases and declines to potential emergence, the increases pale in comparison with the declines.

Unfortunately, habitat data were not available in the 1950s for one of the lower segments (segment $11)$, so estimating river-wide flux in the 1950s was not possible. However, of the segments that did contain data from this decade, all showed a decline from the 1890s to the 1950s (Figure S7; segments 4, $8,10,12$, and 13). Only one of these segments was channelized by the 1950s (segment 13), but it is unclear why predicted emergence declined in the unchannelized segments. The data from the 1950s were taken before or during the construction of most of the mainstem dams (Quist 2014), well before any effects of the fluvial geomorphic processes that created the deltas and subsequent increases in off-channel habitat and emergence. As a result, it seems likely that initial channel incision below dams and agricultural development in the riparian areas contributed to the initial decline of off-channel habitat in the 1950s, but this speculation deserves further study.

Loss of aquatic subsidies might disproportionately contribute to population declines for early successional bird species since early successional habitats typically border the river, so these birds might be most likely to receive aquatic subsidies. Because of the flow regulation-induced decline in early successional riparian habitats since closure of the dams in the 1950s (Dixon and others 2012), early successional bird species may be the most threatened group of riparian forest birds along the Missouri River (Swanson 1999; Munes and others 2015). No uniform regional (central USA) population trends for early successional bird species are evident, although some species including eastern kingbird (Tyrannus tyrannus), brown thrasher (Toxostoma rufum), common yellowthroat (Geothlypis trichas), field sparrow (Spizella pusilla) and orchard oriole (Icterus spurius) show declining population trends from 1966-2015 (Sauer and others 2017), roughly coincident with the period since dam closure on the Missouri River. Nevertheless, because these species are geographically widespread, it seems unlikely that declining aquatic subsidies on the Missouri River alone are a prominent factor contributing to population declines in these species.

The numbers above are derived from measures of insect biomass, but relying on biomass alone may underestimate the importance of aquatic insects to riparian insectivores along the Missouri River. For instance, adult aquatic insects obtain some polyunsaturated fatty acids (PUFAs) from freshwater algae that produce PUFAs. Those PUFAs are not produced by terrestrial plant-based food chains and thus are not present in terrestrial insects (Gladyshev and others 2009; Hixson and others 2015; Popova and others 2017). As a result, the subsidy of aquatic insects to riparian insectivores may provide a critical resource that cannot be obtained simply by switching diets to focus on terrestrial insects. For example, tree swallow chicks had improved growth, condition, and immunocompetence when fed diets containing high levels of PUFAs (proxy for aquatic insects) compared to a diet with low levels (proxy for terrestrial insects) (Twining and others 2016).

Moreover, obtaining aquatic insect prey outside of the floodplain may be difficult for many riparian consumers along the Missouri River due to the relative scarcity of freshwater in the Midwestern USA. The Missouri River flows through the US states of Montana, North Dakota, South Dakota, Nebraska, Iowa, Kansas, and Missouri. Permanent surface water habitat (lakes, wetlands, rivers) in those states covers an average of $1 \%$ of total land area (https://water.usgs.gov/edu/wetstates.html). By comparison, in the nearby states of Wisconsin, surface water covers $17 \%$ of the land area and produces a total insect emergence of 5,400,000 $\mathrm{kgC} / \mathrm{y}$ (Bartrons and others 2013). Because of the relative scarcity of other surface freshwater along the Missouri River, it may be more difficult for riparian insectivores to replace the energetic subsidies that are lost when freshwater habitat in the floodplain disappears.

\section{Caveats}

As with any attempt to scale up from local samples to broad spatial predictions, our results have a number of important caveats. We estimated insect production based only on samples from 2014-2017, but multiplied those estimates by surface area in 
the 1890s. Thus, our estimates effectively assume that areal aquatic insect emergence was constant between 1890 and 2017. We are not aware of historical measures of insect emergence, and so cannot test this assumption. However, between 1963 and 1980, benthic secondary production of macroinvertebrate larvae in one backwater within our study reach declined by $61 \%$ (Mestl and Hesse 1993). If this trend is reflective of adult aquatic insect emergence, then it would suggest that not only has insect emergence declined due to losses in freshwater surface area but perhaps also due to declines in production within remaining habitats. If that is the case, then our estimates of lost production are highly conservative. Alternatively, air temperatures in this region have increased by $\sim 0.5$ to $1^{\circ} \mathrm{C}$ over the past century, particularly in the upper segments of the Missouri River (Hansen and others 2001). Whether this has translated to increases in water temperature is unclear. Insect emergence production is positively related to water temperatures (Bartrons and others 2013), so it is possible that the loss of habitat for emergence has been somewhat offset by temperature-related increases in areal production within those habitats. However, any increase in production due to temperature changes is likely to be small relative to the declines in production from extensive habitat loss.

Our measures of emergence also come from a single reach along the 3767-km-long Missouri River. Along this length, the river flows across 10 degrees of latitude and 22 degrees of longitude. This undoubtedly creates broad variation in local environmental factors that may impact insect production. For example, it is likely that production in warmer, lower latitude habitats will be higher than production in our field sites. In addition, the size, water quality, and food webs of other backwaters are likely to vary considerably beyond our sample sites. We do not have estimates of this variability for the majority of the river. However, it is worth emphasizing that the posterior predictive distribution for insect emergence is slightly lower than the global mean for lakes, but with 95\% credible intervals that range over an order of magnitude and include most estimates of emergence from other lentic habitats. Thus, our model predictions cover a wide range of potential insect production (Figure S4), but should be viewed as testable predictions for future surveys in different locations, perhaps using our posterior distribution as a prior distribution in future studies. In addition, while emergence is certain to vary widely among existing off-channel habitats and among years, the ecological importance of this variation would be small relative to the complete loss of aquatic insect emergence due to habitat loss.

\section{Management Implications}

In the Missouri River, management agencies have attempted to mitigate the loss of off-channel habitats by constructing artificial backwaters and sidechannels (Yager and others 2013). Typically, the justification for these projects is that they will improve the recovery of threatened or endangered fish species (Hesse and others 1994; Sterner and others 2009; Dzialowski and others 2013; Yager and others 2013). This is undoubtedly true, but our data indicate that these benefits may extend to riparian insectivores. The potential for backwater habitat restoration to impact riparian insectivores like birds provides an additional justification for these projects beyond their importance to freshwater floodplain ecosystems (Tockner and Stanford 2002). For example, in the Missouri National Recreational River in 2008, 9\% (21/243 ha) of backwater habitat consisted of restored backwaters (Yager and others 2013). That is enough to subsidize $\sim 700$ birds that obtain $24 \%$ of their annual energy budget from emerging aquatic insects. If production in restored or created backwaters is similar to production in natural backwaters, then our results demonstrate that these restoration efforts could have a substantial impact on riparian insectivores by restoring aquatic-terrestrial subsidies on the landscape.

\section{ACKNOWLEDGEMENTS}

Funding for this study was partially provided by the National Science Foundation (NSF-DEB Award 1837233, NSF-DEB Award 1560048, NSF-OIA Cooperative Agreement 1632810), and from the University of South Dakota. Dr. Malia Volke designed the study area map. Funding for GIS mapping was provided via contracts \#W912HZ-12-20009 and \#W912DQ-07-C-0011 from the US Army Corps of Engineers (USACE), and a contract from the Louis Berger Group, Inc. For contract \#W912HZ-12-2-0009, contracting to the University of South Dakota was facilitated through the Great Plains Cooperative Ecosystem Studies Units (GPCESU). Funding for bird work that supported the density estimates was provided by a Wildlife Diversity Small Grant from the South Dakota Department of Game, Fish, and Parks and the two USACE contracts mentioned above. Additional support for Swanson and Dixon was provided by NSF EPSCoR Track II cooperative agreement \# OIA-1632810. This study was conducted under the 
approval of the National Park Service (Permit \#s: MNRR-2014-SCI-0004, MNRR-2015-SCI-0005, MNRR-2017-SCI-0003， MNRR-2018-SCI-0002). This material is based upon work supported by the National Science Foundation Graduate Research Fellowship Program to TCS under Grant No. NSF DBI-1839286. Any opinions, findings, and conclusions or recommendations expressed in this material are those of the author(s) and do not necessarily reflect the views of the National Science Foundation.

\section{REFERENCES}

Aarts BGW, Van Den Brink FWB, Nienhuis PH. 2004. Habitat loss as the main cause of the slow recovery of fish faunas of regulated large rivers in Europe: the transversal floodplain gradient. River Res Appl 20:3-23.

Allen DC, Wesner JS. 2016. Synthesis: comparing effects of resource and consumer fluxes into recipient food webs using meta analysis. Ecology 97:594-604. http://onlinelibrary.wile y.com/doi/10.1890/15-1109.1/full.

Anderson KJ, Jetz W. 2005. The broad-scale ecology of energy expenditure of endotherms. Ecol Lett 8:310-18.

Bartrons M, Papeş M, Diebel MW, Gratton C, Vander Zanden MJ. 2013. Regional-level inputs of emergent aquatic insects from water to land. Ecosystems 16:1353-63.

Baxter CV, Fausch KD, Carl Saunders W. 2005. Tangled webs: reciprocal flows of invertebrate prey link streams and riparian zones. Freshw Biol 50:201-20.

Benke AC. 2001. Importance of flood regime to invertebrate habitat in an unregulated river-floodplain ecosystem. J North Am Benthol Soc 20:225-40.

Benson A. 2011. Effects of forest type and age class on songbird populations across a cottonwood successional gradient along the Missouri River. (Master's Thesis), University of South Dakota.

Bürkner P-C. 2017. Advanced Bayesian Multilevel Modeling with the R Package brms. https://journal.r-project.org/archiv e/2018/RJ-2018-017/RJ-2018-017.pdf.

Cadmus P, Pomeranz JPF, Kraus JM. 2016. Low-cost floating emergence net and bottle trap: comparison of two designs. J Freshw Ecol 31:653-8.

Cummins KW, Wuycheck JC. 1971. Caloric equivalents for investigations in ecological energectics: with 2 figures and 3 tables in text. Internationale Vereinigung für Theoretische und Angewandte LImnologie: Mitteilungen 18:1-158.

Dixon MD, Johnson WC, Scott ML, Bowen DE, Rabbe LA. 2012. Dynamics of plains cottonwood (Populus deltoides) forests and historical landscape change along unchannelized segments of the Missouri River, USA. Environ Manage 49:9901008.

Dunning JB. 2007. CRC Handbook of Avian Body Masses, Second Edition. CRC Press.

Dutenhoffer MS, Swanson DL. 1996. Relationship of basal to summit metabolic rate in passerine birds and the aerobic capacity model for the evolution of endothermy. Physiol Zool 69:1232-54.

Dzialowski AR, Bonneau JL, Gemeinhardt TR. 2013. Comparisons of zooplankton and phytoplankton in created shallow water habitats of the lower Missouri River: implications for native fish. Aquat Ecol 47:13-24.

Epanchin PN, Knapp RA, Lawler SP. 2010. Nonnative trout impact an alpine-nesting bird by altering aquatic-insect subsidies. Ecology 91:2406-15.

Funk JL, Robinson JW. 1974. Changes in the channel of the lower Missouri River and effects on fish and wildlife. Aquatic Ser Missouri Dep Conserv.

Galat DL, Berry CR, Gardner WM, Hendrickson JC, Mestl GE, Power GJ, Stone C, Winston MR. 2005. Spatiotemporal patterns and changes in Missouri River fishes. American Fisheries Society Symposium 45:249-91.

Galat DL, Fredrickson LH, Humburg DD, Bataille KJ, Bodie JR, Dohrenwend J, Gelwicks GT, Havel JE, Helmers DL, Hooker JB, Jones JR, Knowlton MF, Kubisiak J, Mazourek J, McColpin AC, Renken RB, Semlitsch RD. 1998. Flooding to restore connectivity of regulated, large-river wetlands: natural and controlled flooding as complementary processes along the lower Missouri River. Bioscience 48:721-33.

Gladyshev MI, Arts MT, Sushchik NN. 2009. Preliminary estimates of the export of omega-3 highly unsaturated fatty acids (EPA+DHA) from aquatic to terrestrial ecosystems. In: Kainz M, Brett MT, Arts MT, editors. Lipids in Aquatic Ecosystems. New York, NY: Springer New York. pp 179-210.

Gratton C, Vander Zanden MJ. 2009. Flux of aquatic insect productivity to land: comparison of lentic and lotic ecosystems. Ecology 90:2689-99.

Grubaugh JW, Anderson RV. 1988. Spatial and temporal availability of floodplain habitat: long-term changes at pool 19 , Mississippi River. Am Midl Nat 119:402-11.

Hamilton SK. 2009. Wetlands of Large Rivers: Flood plains. In: Likens GE, Ed. Encyclopedia of Inland Waters. Oxford: Academic Press. p 607-10.

Hastie TJ. 2017. Generalized Additive Models. Routledge.

Hesse LW, Mestl GE, Robinson JW. 1994. Status of Selected Fishes in the Missouri River in Nebraska With Recommendations for Their Recovery. Nebraska Game and Parks Commission - Staff Research Publications. 22.

Hixson SM, Sharma B, Kainz MJ, Wacker A, Arts MT. 2015. Production, distribution, and abundance of long-chain omega-3 polyunsaturated fatty acids: a fundamental dichotomy between freshwater and terrestrial ecosystems. Environ Rev 23:414-24.

Hoekman D, Dreyer J, Jackson RD, Townsend PA, Gratton C. 2011. Lake to land subsidies: experimental addition of aquatic insects increases terrestrial arthropod densities. Ecology 92:2063-72.

Johnson WC, Burgess RL, Keammerer WR. 1976. Forest overstory vegetation and environment on the Missouri river floodplain in North Dakota. Ecol Monogr 46:59-84.

Kennedy TA, Muehlbauer JD, Yackulic CB, Lytle DA, Miller SW, Dibble KL, Kortenhoeven EW, Metcalfe AN, Baxter CV. 2016. Flow management for hydropower extirpates aquatic insects, undermining river food webs. BioScience 66:561-75.

Liu M. 2015. Physiological and ecological measures of stopover habitat quality for migrant birds in natural riparian corridor woodlands and anthropogenic woodlots in southeastern South Dakota. (Doctoral dissertation, University of South Dakota).

Liu M, Swanson DL. 2014. Physiological evidence that anthropogenic woodlots can substitute for native riparian woodlands 
as stopover habitat for migrant birds. Physiol Biochem Zool 87:183-95.

Malison RL, Benjamin JR, Baxter CV. 2010. Measuring adult insect emergence from streams: the influence of trap placement and a comparison with benthic sampling. J N Am Benthol Soc 29:647-56.

Mestl GE, Hesse LW. 1993. Secondary productivity of aquatic insects in the unchannelized Missouri River, Nebraska. Pages 341-349 in Hesse LW, Stalnaker CB, Benson NG, Zuboy JR, eds. Restoration Planning for the Rivers of the Mississippi River Ecosystem. Washington (DC): US Department of Interior, National Biological Survey. Biological Report 19. http:// naturalresources.intersearch.com.au/naturalresourcesjspui/ handle/1/2301.

Morris LA, Langemeier RN, Russell TR, Witt A. 1968. Effects of Main Stem Impoundments and Channelization upon the Limnology of the Missouri River, Nebraska. Trans Am Fish Soc 97:380-8.

Munes EC, Dixon MD, Swanson DL, Merkord CL, Benson AR. 2015. Large, infrequent disturbance on a regulated river: response of floodplain forest birds to the 2011 Missouri River flood. http://doi.wiley.com/10.1890/ES15-00007.1.

Nakano S, Murakami M. 2001. Reciprocal subsidies: dynamic interdependence between terrestrial and aquatic food webs. Proc Natl Acad Sci USA 98:166-70.

Poff NL, Allan JD, Bain MB, Karr JR, Prestegaard KL, Richter BD, Sparks RE, Stromberg JC. 1997. The Natural Flow Regime. Bioscience 47:769-84.

Popova ON, Haritonov AY, Sushchik NN, Makhutova ON, Kalachova GS, Kolmakova AA, Gladyshev MI. 2017. Export of aquatic productivity, including highly unsaturated fatty acids, to terrestrial ecosystems via Odonata. Sci Total Environ 581582:40-8.

Quist DJ. 2014. Historical changes and impacts of the 2011 flood on channel complexity on the missouri river. MS Thesis, University of South Dakota.s. https://search.proquest.com/d ocview/1658567610.

R Core Team. 2017. R: a language and environment for statistical computing. Vienna, Austria: R Foundation for Statistical Computing; 2017.

Richardson JS, Sato T. 2015. Resource subsidy flows across freshwater-terrestrial boundaries and influence on processes linking adjacent ecosystems. Ecohydrology 8:406-15.

Sabo JL, Power ME. 2002. River-watershed exchange: effects of riverine subsidies on riparian lizards and their terrestrial prey. Ecology 83:1860-9.

Sauer, JR, Niven DK, Hines, JE, Ziolkowski Jr, DJ, Parkieck, KL, Fallon, FE, and Link, WA. 2017. The North American Breeding Bird Survey, Results and Analysis 1966 - 2015. Version 2.07.2017 USGS Patuxent Wildlife Research Center, Laurel, MD.

Swanson DL. 1999. Avifauna of an early successional habitat along the middle Missouri River. Prairie Naturalist 31:145-64.
Stan Development Team. 2016. RStan: the R Interface to Stan. R Package Version 2.14.1

Sterner V, Bowman R, Eder BL, Negus S, Mestl G, Whiteman K, Garner D, Travnichek V, Schloesser J, McMullen J, Hill T. 2009. Final Report - Missouri River Fish and Wildlife Mitigation Program: Fish Community Monitoring and Habitat Assessment of Off-channel Mitigation Sites. https://digitalco mmons.unl.edu/nebgamestaff/57/. Last accessed 23/08/2018.

Swanson DL. 2010. Seasonal Metabolic Variation in Birds: Functional and Mechanistic Correlates. In: Thompson CF, editor. Current Ornithology Volume 17. New York, NY: Springer New York. pp 75-129.

Swanson DL, Liknes ET. 2006. A comparative analysis of thermogenic capacity and cold tolerance in small birds. J Exp Biol 209:466-74.

Tallman DA, Swanson DL, Palmer JS. 2002. Birds of South Dakota. Aberdeen, South Dakota: South Dakota Ornithologists' Union, Northern State University.

Tockner K, Stanford JA. 2002. Riverine flood plains: present state and future trends. Environ Conserv 29:308-30.

Twining CW, Brenna JT, Lawrence P, Shipley JR, Tollefson TN, Winkler DW. 2016. Omega-3 long-chain polyunsaturated fatty acids support aerial insectivore performance more than food quantity. Proc Natl Acad Sci USA 113:10920-5.

Volke MA, Scott ML, Johnson WC, Dixon MD. 2015. The ecological significance of emerging deltas in regulated rivers. BioScience 65:598-611.

Warmbold J. 2016. Effects of fish on aquatic and terrestrial ecosystems. MS Thesis, University of South Dakota. https:// search.proquest.com/docview/1819287883.

Warmbold JW, Wesner JS. 2018. Predator foraging strategy mediates the effects of predators on local and emigrating prey. Oikos 127:579-89.

Whiles MR, Goldowitz BS. 2001. Hydrologic influences on insect emergence production from central Platte river wetlands. Ecol Appl 11:1829-42.

Whiles MR, Goldowitz BS. 2005. Macroinvertebrate communities in central Platte River wetlands: Patterns across a hydrologic gradet alient. Wetlands 25:462-72.

Whitley JR, Campbell RS. 1974. Some aspects of water quality and biology of the Missouri River. Trans Mo Acad Sci 8:60-72.

Wohl E, Bledsoe BP, Jacobson RB, Poff NL, Rathburn SL, Walters DM, Wilcox AC. 2015. The Natural Sediment Regime in Rivers: Broadening the Foundation for Ecosystem Management. Bioscience 65:358-71.

Wood SN. 2017. Generalized additive models: an introduction with R. https://www.taylorfrancis.com/books/978149872834 8.

Yager LA, Dixon MD, Cowman TC, Soluk DA. 2013. Historic changes (1941-2008) in side channel and backwater habitats on an unchannelized reach of the Missouri River. River Res Appl 29:493-501. 